\title{
We Still Find It Exciting
}

Dear Reader,

It is a privilege for a technical magazine to be able to cover 120 years of motoring history. During this time ATZ has reported on many groundbreaking developments and quite a few that were less significant. Looking back, it is clear that many technical advances were made decades ago, but then disappeared almost without trace. One good example is electric cars. They were a familiar sight on our roads until the early 1920s, and interesting developments in this area were also made in the 1950s. After that, progress came to a halt and it is only in the last few years that electric vehicles have become popular again. Other technologies, such as rear-wheel steering for cars, have still not taken off, despite some promising initiatives over the years.

This special issue on the occasion of the $120^{\text {th }}$ anniversary of ATZ naturally includes a look back over twelve decades of developments in the automotive world. But it also looks forward to the years to come, which are likely to involve major changes. Electric vehicles, the solutions needed for the transport problems of a growing number of large cities, the aging populations in many countries, and a very different approach to mobility among the younger generation of customers will bring about a major transformation in transport in many areas. One of the key issues facing the automotive industry today is designing efficient, customer-focused mobility and transport solutions and understanding the impact that these will have on car manufacturers and their suppliers. These exciting developments will keep us busy over the next few years and decades, because the members of the editorial team at ATZ are just as fascinated by automotive engineering as you, the magazine's readers.

We hope you enjoy reading "120 Years of ATZ."
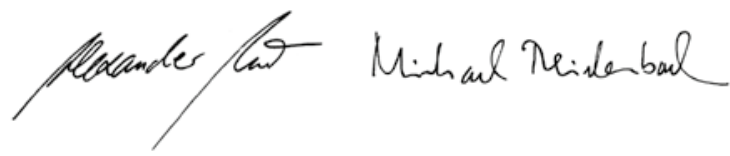

Dr. Alexander Heintzel Editor in Chief
Dipl.-Ing. Michael Reichenbach Deputy Editor in Chief

\section{Interior 40}

\section{Ready for the future}

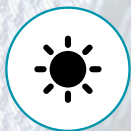

Interior lighting $\mathbf{2 . 0}$ individual light scenarios as central elements for complete comfort

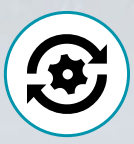

Function integration Intergration of flexible system and smarter surfaces

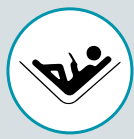

Autonomous ready drive, work \& relax: mobile space for work and relaxation

Looking for more? future@draexImaier.com 